\title{
Nutraceuticals: Curative Integrative Cancer Treatment
}

\section{Oroma B Nwanodi*}

Department of Obstetrics and Gynecology, Locum Tenens, Salinas CA, USA

*Corresponding author: Nwanodi OB, Department of Obstetrics and Gynecology Locum Tenens, P. O. Box 59, Salinas, CA-93902-0059, USA. Tel: 13143042946; Email: o.nwanodi@juno.com

Received date: May 22, 2017; Accepted date: June 12, 2017; Published date: June 20, 2017

Copyright: (c) 2017 Nwanodi OB. This is an open-access article distributed under the terms of the Creative Commons Attribution License, which permits unrestricted use, distribution, and reproduction in any medium, provided the original author and source are credited.

\begin{abstract}
Statement of Purpose: Although $75 \%$ of breast cancer patients may use integrative medicine, only $11.5 \%$ earlystage breast cancer patients believe integrative medicine has anticancer activity. The gap in users of and firm believers in integrative medicine indicates a need to increase awareness of integrative medicine's applicability to curative cancer treatment. As diet, nutraceuticals, and traditional Chinese medicine are used by up to $82 \%$ of cancer patients who use integrative medicine, this paper focuses on nutraceuticals. As female cancer patients are most likely to use integrative medicine, nutraceuticals specific to breast, cervical, endometrial, and ovarian cancer are reviewed.
\end{abstract}

Methods: PubMed searches in September 2016 and January 2017, and accompanying hand searches were performed for English language, free full text articles published from 2012 onwards. Search terms were combinations of the key words: Homeopathy, phytochemicals, breast cancer, cervical cancer, endometrial cancer, ovarian cancer, cancer, prevention, treatment. Curative nutraceutical treatments were taken from these searches. Supplemental hand searches were performed as needed.

Findings: Integrative nutraceutical therapies are based on biologic plausibility. Individual nutraceuticals are frequently comprised of numerous phytochemical types, and have multiple mechanisms of action. Agonistantagonist mechanisms are not exclusive to phytoestrogens, complicating which derivative or whole nutraceutical to use. Research on breast and cervical cancer inhibitors has seemingly outpaced that for endometrial and ovarian cancer. Breast cancer inhibitors include terpenes, isoflavones, organosulphurs, organoselenium compounds, and withanolides.

Conclusion and Significance: Potential nutraceutical candidates for curative cancer treatment abound. Discerning which constituents, which extraction method, and which delivery method to use for an efficacious treatment is an essential, lengthy process. If nutraceuticals such as limonene and Kahalalide $F$ move forward to Phase III trials a nutraceutical cancer treatment pipeline may be established. Withaferin-A and derivatives for breast and ovarian cancer appear to be the leading gynecologic cancer nutraceutical drug candidates.

Keywords: Cancer treatment; Integrative cancer treatment; Naturopathic medicine; Nutraceuticals; Phytochemicals; Phytonutrients; Traditional chinese medicine

\section{Introduction}

One-time integrative medicine use ranges from $42 \%$ in the United States to $75 \%$ in France [1]. Upon cancer diagnosis patients are interested in conventional and integrative therapies [2]. Post cancer diagnosis, $17 \%$ of Italian, $27 \%$ of Austrians, $35.9 \%$ of Europeans overall, $44 \%$ of German gynecologic cancer, $47.2 \%$ of Canadian, and $50 \%$ of German breast cancer patients use integrative medicine therapies [2-6]. Consistent with this, integrative gynecologic cancer treatment is regarded as reasonable by $44.5 \%$, and practiced by $24.2 \%$ of 310 Hessian region ObGyns who responded to a survey at an educational meeting [7]. Nonetheless, extremes in integrative cancer treatment are evident. In one study, $75 \%$ of breast cancer patients used integrative medicine [8]. However, as few as $11.5 \%$ of early stage breast cancer patients may perceive integrative medicine as having anticancer activity [9]. Pediatric oncology integrative medicine ranges from $12 \%$ to $42 \%$ in Europe and $25 \%$ to $82 \%$ in the United States [1].
In Dutch pediatric oncology patients, female gender is predictive of integrative cancer use [10]. Similarly, a cross-sectional study of three Pennsylvanian oncology centers found that being female $(\mathrm{p}=0.005)$, having breast cancer $(\mathrm{p}=0.016)$, and being at 12 to 36 months post diagnosis $(\mathrm{p}=0.017)$ most associated with integrative cancer treatment [11]. Time from diagnosis had an $\mathrm{n}$ shaped association with integrative cancer treatment [11]. Herbal and traditional Chinese medicine (TCM; excluding acupuncture) are received by $74.5 \%$ of patients at European integrative oncology centers [6]. Among Italian cancer patients as few as $38.3 \%$ currently and as many as $84.2 \%$ previously used nutraceuticals comprised of diet, dietary supplements, and herbs [12].

\section{Nutraceuticals}

Nutraceuticals range from active constituent phytochemicals, minerals, and vitamins, through whole functional foods [13]. Integrative nutraceutical therapies are based on biologic plausibility and have played an historical role in the development of the prescription pharmaceutical industry [14]. Willow bark derived analgesic aspirin, Aspergillus terreus derived cholesterol-lowering lovastatin, Camellia sinensis (green tea) polyphenols derived 
sinecatechins for Condyloma acuminata (external genital wart [EGW]) treatment, Podophyllum species derived podophyllin for EGW and Molluscum contagiosum, as well as the chemotherapeutics taxol derived from Taxus brevifolia (Pacific yew tree), taxotere derived from Taxus baccata (European yew tree), topotecan derived from Camptotheca acuminata, and vincristine derived from Catharanthus roseus (Madagascar periwinkle), are just a few examples [15,16]. Thus historically, nutraceuticals have been a starting point of new pharmaceutical drug development.

Nutraceuticals may provide benefits in conservative serving sizes: A cup of appropriately prepared green tea can provide 300 to $1,000 \mathrm{mg}$ of epigallocatechin-3-gallate (EGCG) [17]. Clinical trial EGCG dosing is based $10 \mathrm{mg} / \mathrm{kg}$ body weight, which can be achieved from green tea [18]. Pharmaceuticals may require enormous amounts of the biologic source: 1,520 Taxus chinensis (Chinese yew) trees, an endangered species, are used to produce $1 \mathrm{~kg}$ of paclitaxel [19]. Therefore, pharmaceuticals may require partially or totally synthetic manufacturing processes including plant cell suspension cultures to preclude extinction of their natural sources [19].

Most pharmaceuticals require a health care providers' prescription, whereas nutraceuticals, being food or dietary supplement products with health modifying effects do not require a prescription [20]. Thus, nutraceuticals lie in a gray zone between prescription pharmaceuticals and open market household items [13]. Nonetheless, nutraceutical agriculture and manufacturing may have to comply with good agricultural practices, good manufacturing practices, and standard operating procedures [21]. Nutraceuticals undergo in vitro and in vivo pharmacokinetic, pharmacologic, therapeutic, safety, and head-tohead comparative effectiveness studies as do pharmaceuticals [20]. Clinical pharmacology studies of nutraceuticals are essential for nutraceutical development and delineation [22]. Nutraceuticals' use as prophylaxis against and treatment of pharmaceuticals' adverse effects is the subject of a separate paper, which also addresses nutraceuticals' inherent adverse effects. This paper reviews nutraceuticals as curative (alternative) cancer treatment, focusing on gynecologic cancer treatment.

\section{Methods}

PubMed searches in September 2016 and January 2017, and hand searches in August 2016, January 2017, and March 2017 were performed for English language, free full text articles published from 2012 onwards. Search terms were combinations of the key words: Homeopathy, phytochemicals, breast cancer, cervical cancer, endometrial cancer, ovarian cancer, cancer, prevention, and treatment. Curative nutraceutical treatments were taken from these searches, as shown in Figure 1. Cytotoxic treatments and nutraceutical mechanisms of action were taken from these searches. These searches retrieved 184 articles, of which 127 articles were from the PubMed searches and 57 articles were from content driven hand searches. Of these, there were 14 duplicate articles, 16 redundant articles, and 55 extraneous articles, resulting in a total of 85 excluded and 99 included articles.

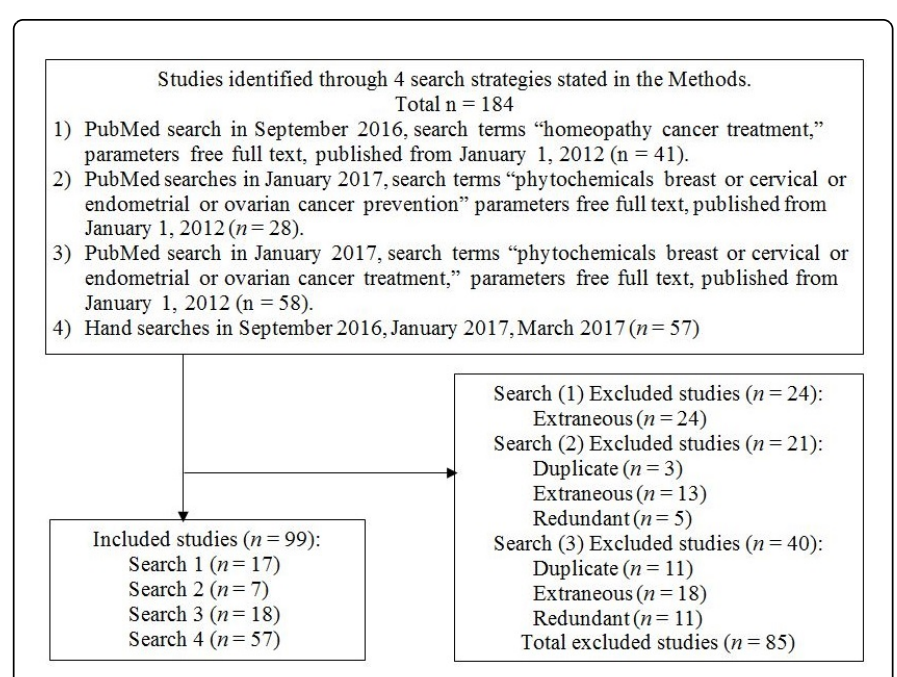

Figure 1: Literature selection flowchart.

\section{Nutraceuticals by phytochemical classification}

This study does not review vitamins and minerals per se. However, whole fruits and vegetables, and fruit and vegetable derived phytochemicals may be vitamin and mineral rich. Fruit and vegetable derived phytochemicals may be studied based on mechanism of action, pathologies treated, or biochemical classification. By mechanism of action, the Matrix MetalloProtease (MMP) inhibitors aqueous cinnamon extract, green tea extract, curcumin, fenugreek derived steroidal saponin, and marine compound derived chitooligosacharides would be grouped together. However, each of these nutraceuticals has multiple mechanisms of action. Therefore, nutraceuticals and cancer treatment capabilities are initially presented based on chemical classification. There are numerous biochemical nutraceutical categories including alkaloids, lipids, organic acids and polysaccharides, organosulphurs, phenols, phytic acids, phytosterols, and terpenes, as indicated in Figure 2. Functional foods and other nutraceuticals comprised of constituent compounds will have constituent compounds from multiple biochemical classifications. The encompassing groups of alkaloids, organic acids, and polysaccharides will be briefly mentioned. Nutraceuticals from the secondary and tertiary groups will be briefly mentioned. Then attention will turn to those nutraceuticals pertinent to breast, cervical, and ovarian cancer treatment.

\section{Alkaloids}

Alkaloids are physiologically active, vegetable-based, organic, nitrogen-containing ring compounds. Alkaloids may belong to additional biochemical phytonutrient groups based on further chemical structure definition and resultant activity. Alkaloids can be co-constituents of a functional food, as is the case with Camellia sinensis tea leaves, which also contain flavonoids, steroids, gallic tannins and catecholic tannins (flavanols) [23]. There are numerous alkaloid sub-classifications: Coffee derives aroma from trigonelline, a bitter alkaloid, and bitter taste from caffeine, a purine-like alkaloid [24]. Alkaloids include colchicine from Colchicum autumnale (autumn crocus or meadow saffron), scopolamine/hyoscine from Hyoscyamus niger (henbane or stinking nightshade), physostigmine from Physostigma venenosum (Calabar bean), reserpine from 
Page 3 of 12

Rauwolfia serpentine (Indian snakeroot or devil pepper), and taxol from Taxus brevifolia (Pacific yew) [24].

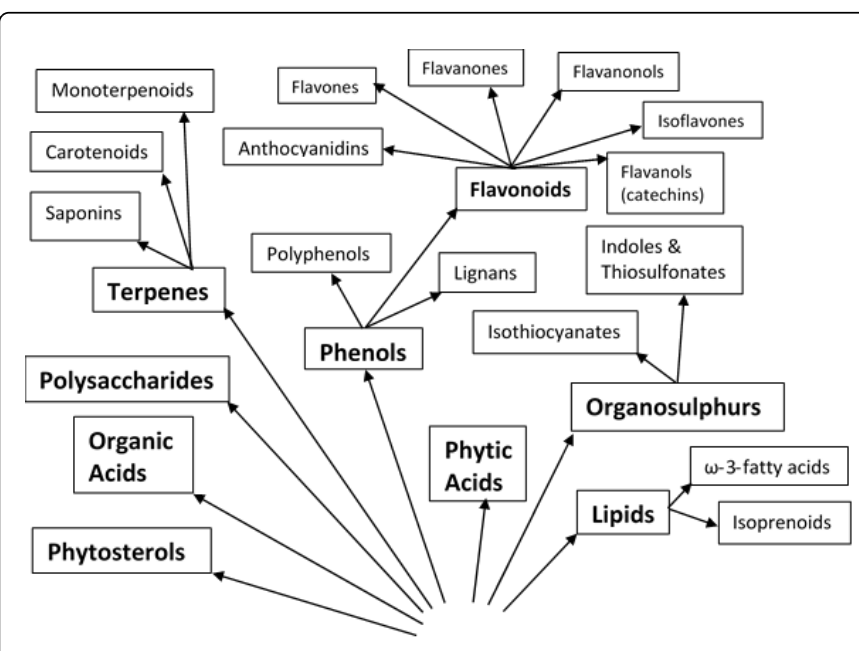

Figure 2: Nutraceuticals biochemical classification.

\section{Organic acids and polysaccharides}

Organic acids and polysaccharides are mentioned first as these are encompassing chemical composition groupings. Constituents thereof will belong to additional biochemical phytonutrient groups based on chemical structure and resultant activity. Organic acids are carbon containing acids. Polysaccharides are comprised of bonded sugar molecules.

Organic acids: Organic acids are inflammatory mediators with antioxidant, chemopreventive, and hepatoprotective properties [25]. Cinnamic acid in Aloe vera, ellagic acid (a polyphenol organic acid, found in berries, green tea, guava, pecans, and walnuts), ferulic acid in oats and rice, gallic acid in tea, oxalic acid in coffee, spinach, and tea, and salicylic acid in peppermint are a few examples [25]. Ellagic acid is a reactive epoxide scavenger that inhibits DNA methylation and DNA topoisomerase [26].

Polysaccharides: Mushrooms are immune boosting chemopreventive polysaccharides [25]. Fibrous polysaccharides also bind carcinogens, lower bile acids, and modulate estrogen metabolism [26]. Polysaccharides from the TCM adaptogen ginseng up regulates granzyme and perforin expression and increases the whole blood natural killer cell (NKC) concentration leading to increased NKC cytotoxicity and decreased radiation therapy adverse effects [27]. Perforin forms pores in target cells allowing serine protease granzyme to diffuse into target cells and initiate apoptosis.

\section{Organosulphur compounds}

Sulphur's pungent odor is a hallmark of the organosulphur compounds comprised of indoles, thiosulfonates, and isothiocyanates. Organosulphur compounds, which include indole-3-carbinol (I3C) and diindolylmethane (DIM), are commonly derived from cruciferous vegetables. Cephalosporins which were developed from Acremonium fungi and penicillin from Penicillium fungi are also organosulphurs.

Indoles and Thiosulfonates: Indoles and thiosulfonates result from the ingestion and digestion of some cruciferous vegetables [25,28].
Indoles induce and activate cytochrome $\mathrm{P} 450$ for phase I detoxification [25]. In $\mathrm{A} / \mathrm{J}$ mice, I3C inhibits lung adenoma [28]. In BALB/c mice DIM inhibits lung metastasis [28]. While I3C is rapidly hydrolyzed in the stomach, hydro and lipo-phobic DIM requires combination with vitamin $\mathrm{E}$ and phosphatidylcholine for bioavailability [28].

Isothiocyanates: Allium compounds found in garlic induce glutathione s-transferase (GST) and microsomal monooxygenases [26]. Garlic, onion, and turnips are isothiocyanate sources. Cabbage, garden cress, and Indian cress derived benzyl isothiocyanate (BITC) and watercress derived phenethyl isothiocyanate (PEITC) may be less studied than the phenols, terpenes, and thiosulfonates that are also found in allium containing vegetables [29,30]. Nonetheless, BITC activates AP-1, caspase-3, MAPK, and NF- $\kappa \beta$ while inhibiting other protein kinases [31]. BITC induces apoptosis, G2/M phase cell-cycle arrest, glutathione depletion, and reactive oxygen species (ROS) generation [31]. PEITC inhibits phase I enzymes but activates phase II enzymes [31].

\section{Lipids}

There are numerous lipid subgroups including fats, waxes, glycolipids, phospholipids, and polyprenyl compounds. Steroids, fatsoluble vitamins, and isoprenoids (terpenoids) are polyprenyl compounds. Omega-3- and omega-6-polyunsaturated fatty acids (PUFAs) are essential fatty acids [25].

Isoprenoids: Isoprenoids enhance antioxidative power by improving receptor functionality [25]. Farnesol (from floral essential oil) and geraniol (from citronella, geranium, lemon, palmarosa, and rose oils) have in vivo cytotoxicity against murine liver cancer, leukemia, and melanoma [32]. Cell membrane phospholipid bi-layers are protected from free radicals by isoprenoids [25]. Isoprenoids production by microorganisms including Escherichia coli, and Saccharomyces cerevisiae reduces the likelihood of supply limitations $[33,34]$. Therefore, it is biologically plausible and ecologically reasonable that isoprenoid-phospholipid conjugates be studied for potential medicinal purposes [32].

Omega-3-PUFAs: Omega-3-PUFAs are immune boosting, platelet aggregating, anti-inflammatories [25]. Omega-3-PUFAs are consumed as docosahexanoic acid (DHA) and eicosapentanoic acid (EPA) [35]. Omega-3-PUFAs reduce coronary heart disease risk; decrease triglycerides, blood pressure, and inflammatory markers; improve endothelial function; prevent some cardiac arrhythmias; reduce vasoconstriction; enhance fibrinolysis and reduce fibrin formation; and decrease the risk of microalbuminuria and sudden cardiac death [35]. Omega-3-PUFAs form resolvins and protectins, suppress COX-2, IL- $\beta$, and TNF- $\alpha$ [35]. Omega-3-PUFAs bind peroxisome proliferator receptor activator (PPAR) gamma, allowing omega-3-PUFAs to inhibit cell proliferation and induce cancer cell apoptosis [35]. DHA has greater dose dependent pro-apoptotic activity against DU145 prostate carcinoma cells than does EPA. DHA's pro-apoptotic activity is mediated via MAPK, NF- $\kappa \beta$, p53, and PI3K-Akt signaling pathways [36].

\section{Phenols}

Phenols which may be best known for the fruit and vegetable rainbow have a phenylalanine base. Coumarins, flavonoids, lignans, polyphenols, quinones, stilbenes, tannins, and xanthones, comprise the phenols category. Flavonoids in turn are comprised of anthocyanidins, flavones, flavanones, flavanonols, isoflavones, and flavanols. Each 
gram of Camellia sinensis leaf extract contains $700 \mathrm{mg}$ of phenols, of which $14 \mathrm{mg}$ are flavonoids [23].

Coumarins: Coumarins are fragrant benzopyrones. Coumarins are also found in Artemisiascoparia (yin-chen wormwood), Citrus spp. (orange), and Glycyrrhiza uralensis (licorice) [37]. Fungi convert coumarin from moldy Melilotus spp. (sweet clover) to 4hydroxycoumarin that dimerizes to dicoumarol, a variant of which is warfarin [37]. Comparatively high coumarin content differentiates cassia cinnamon (Cinnamomun cassia) from true Ceylon cinnamon, $C$. verum that has minuscule coumarin content [38]. Coumarin's reduction of melanoma recurrence and inhibition of renal-cell carcinoma did not withstand corroborating trials [37]. Coumarin has dose dependent cytotoxicity against the Hep2 cell line [39]. Carbon-4 substituted coumarins are antiproliferative against breast and liver carcinomas [39]. Carbon-4 substituted coumarins inhibit aromatase, protein kinase, quinone reductase induction, sulphatase, $17 \beta-\mathrm{HSD} 3$, Cdc25, DNA intercalation, HDACs, Hsp90, microtubulin, NF- $\kappa \beta$, and TNF- $\alpha$ [40]. Carbon-4 substituted coumarins are also down regulating selective estrogen receptor modulators (SERMs) [40]. A synthetic coumarin with a 4-position methylene thiol linker to a 6-membered heteroaromatic ring (4-Hydrazinyl-2-\{[(6-methyl-2-oxo- $2 \mathrm{H}$ chromen-4-yl) methyl]sulfanyl\}-6-phenylpyrimidine-5-carbonitrile) is cytotoxic to MCF-7 breast cancer and HepG2 hepatocarcinoma cells, IC50 $5.5 \mathrm{mg} / \mathrm{ml}$ and $6.9 \mathrm{mg} / \mathrm{ml}$, respectively [39]. Potential cytotoxicity is indicated with IC50 of $4 \mu \mathrm{g} / \mathrm{ml}$ or $10 \mu \mathrm{M}$ or less [41]. Ferula narthex Bioss (an Ayurvedic spice called "Raw") derived sesquiterpene $(\mathrm{C} 15 \mathrm{H} 24)$ cholorform soluble coumarin, $\mathrm{C} 24 \mathrm{H} 30 \mathrm{O} 4$ has an in vitro IC50 of $14.074 \pm 0.414 \mu \mathrm{g} / \mathrm{ml}$ against PC3 cells [42]. Prediction of Activity Spectra achieved a probability to be active score of 0.303 with human histone acetyltransferase that should correlate with antipancreatic cancer activity [42].

Flavonoids: Flavonoids have a broad mechanism of action array. Flavonoids are antioxidants, anti-angiogenic, anti-proliferative, active oxygen species scavengers, electrophiles, metal chelators, hydrogen peroxide producers, nitrosation inhibitors, and phase I detoxification enzyme modulators [25,26,43]. Flavones, flavanones, flavonols, flavanonols, isoflavones, flavanols, anthocyanidins and anthocyanins comprise the flavonoid category. Flavonoids including apigenin, kaempferol, nobiletin, quercetin, and rutin are found in cocoa, edible fruits, leafy vegetables, herbs, spices, legumes, tea and red wine $[25,26]$. Rutin, a compound flavonol-disaccharide found in citrus fruits is the primary active ingredient of the homeopathic treatment Ruta [44]. Rice bran oil tricin arrests MDA MB 468 breast cancer cells in G2/M phase [45].

Anthocyanidins and anthocyanins: This group includes cyanidin, delphinidin, malvidin, peonidin, and petunidin, which are found in blueberries $[43,46]$. Carob fruit contains delphinidin, pelargonidin and cyanidin [47]. Delphinidin is an anthocyanidin that affects NF- $\kappa \beta$ regulation [47]. Cyanidin-3-0- $\beta$-glucopyranoside (C3G) from pigmented oranges, berries, and grapes activates caspase-3 in DU145 cells, and induces p 21 protein expression in LnCap cells, resulting in antiproliferative effects against DU145 and LnCap prostate cancer cell lines [48]. C3G is associated with increased concentration of P75NGFR tumor suppressor from normal-like cell phenotype [48]. C3G antioxidant effect may be specific to androgen-independent tumors [48]. C3G has dose dependent ROS activity, requiring $100 \mu \mathrm{M}$ [48].

Flavanonol: Dihydrokaempferol has been isolated from the roots of Smilax bockii and from S. glabra (sarsaparilla) rhizomes [49]. Both
Smilax bockii and $S$. glabra are used in TCM [49]. The leaves of $S$. glycyphylla (sweet sarsaparilla) contain (2R,3R)-dihydrokaempferol-3O- $\beta$-D-glucopyranoside [49]. S. china yields dihydrokaempferol and dihydrokaempferol-3-O- $\alpha$-L-rhamnoside, which are less apoptotic to MCF-7 and MDA-MB-231 than are resveratrol and oxyresveratrol [49]. Taxifolin (dihydroquercetin) is a constituent of milk thistle seeds' silymarin extract and $S$. glabra rhizome [49]. Taxifolin-3-O-glycoside is one of the major active constituents of the tuber of $S$. china [49]. Like dihydrokaempferol and dihydrokaempferol-3-O- $\alpha$-L-rhamnoside, taxifolin is weakly cytotoxic [50].

Flavanones: The flavanones hesperetin and naringenin undergo transformation by neohesperidose and rutinose becoming flavanone glycosides hesperidin, neohesperidin, narirutin, and naringin [51]. Hesperetin is apoptotic to A431 epidermoid skin carcinoma via cyclin and MAPK regulation [51]. Naringenin is effective against A431, B16F10 melanoma, and in vivo HepG2 cells [51]. In murine models, Naringenin dosed at $50 \mathrm{mg} / \mathrm{kg}$ body weight suppresses lung cancer [51]. Naringenin induces G0/G1 and G2/M phase cell cycle arrest, ROS generation, and down regulates TGF- $\beta 1$ [51]. Naringenin induces mitochondrial apoptosis via Bax, Bcl-2, caspase-3, and p53 [51]. Naringenin modulates CYP1A1, NF- $\kappa \beta$ and PCNA [51]. Hesperidin (IC50 $=150.43 \mu \mathrm{M}$ ), is more cytotoxic than naringin and neohesperidin against HepG2, and is also anti-proliferative and apoptotic against A549 lung cancer and NCI-H358 non-small cell lung cancer (NSCLC) cells [51]. Hesperidin activates Erk, MMPs, mitochondrial calcium overload, ROS production, and membrane potential loss, while modulating fibroblast growth factor and NF- $\kappa \beta$ pathways [51]. Naringin activates caspase- 8 and caspase-9 [51]. Naringin inhibits MAPK-AP1 and IKKs-IкB-NF- $\kappa \beta$ pathways [51].

Flavones: Citrus fruit derived flavones include apigenin, chrysoeriol, diosmetin, and luteolin. Apigenin and luteolin have other sources, including celery and parsley [43]. Polymethoxyflavones (PMF) are unique to citrus species' peels, thus used in TCM [52]. Tangeretin, a tangerine derived PMF is anti-inflammatory in microglial cells, suppresses adipocyte storage of triglycerides, and induces G1 arrest or apoptosis in cancer cells [52]. Tangeretin and nobiletin (another PMF) are antiproliferative to A549, MCF-7 and MDA-MB-435 breast cancer, HT-29 colon cancer, and HL-60 leukemia cell lines [51,53,54]. Nobiletin decreases Bcl-2 and increases Bax, leading to G2/M phase cell cycle arrest and apoptosis [51]. Nobiletin modulates hypoxia-TGFinduced epithelial-mesenchymal transition, inhibits notch-1 and TGF$\beta 1 /$ Smad3 signaling, while promoting microRNA-200b re-expression [51]. In vitro, the tangeretin derivative 5-AcTMF is antiproliferative to MCF-7, the U226 myeloma and CL1-5 NSCLC cell lines [52]. The tangeretin derivative 5-demethyltangeretin is more cytotoxic than tangeretin against A549, H460, and HI299 cell lines, with 79, 57 and 56 fold lower IC50 respectively [51]. The nobiletin derivative 5demethylnobiletin has demonstrated in vivo antiproliferative activity against human NSCLC [51].

Flavonols: Tea is the source of several flavanols: Epicatechin (EC), epigallocatechin (EGC), epicatechin-3-gallate (ECG), EGCG, galloyl polyphenol, thearubigin, and theaflavins [43]. Green tea derived galloyl polyphenol and EGCG decrease retinoblastoma protein $(\mathrm{Rb})$ phosphorylation, arresting cells in G1 phase [55]. The green tea polyphenols reactivate tumor suppressor genes by demethylation [55]. Green tea has the most EGCG, then white tea, and least of all black tea. Black tea derived thearubigin and theaflavins are anti-angiogenic [43]. The constituent epicatechin of Maytenus buchananii (a small evergreen 
tree), a traditional Cameroonian anti-cancer treatment, has an excellent MIC of 32 to $128 \mu \mathrm{g} / \mathrm{ml}$ against Staphylococcus aureus [56].

Other flavonols include quercetin from apples, berries, and red onions, and kaempferol from citrus fruits [43]. Luteolin and quercetin induce apoptosis in TRAIL-resistant cancer cells. Kaempferol, luteolin, and quercetin have shown dose dependent reduction in OVCAR3 ovarian cancer growth and VEGF production [25]. Quercetin is cytotoxic to papillary urothelial carcinoma T24 cells, p<0.05 [57]. $M$. buchananii quercetin has an EC50 of $1.38 \mu \mathrm{g} / \mathrm{ml}$ and a TEAC of 89.69 $\mu \mathrm{g} / \mathrm{ml}$. M. buchananii quercetin-3-O- $\alpha$-L-rhamnopyranoside has an EC50 of $1.56 \mu \mathrm{g} / \mathrm{ml}$ and TEAC of $90.93 \mu \mathrm{g} / \mathrm{ml}$. M. buchananii quercetin-3-O- $\beta$-D-glucopyranoside has a MIC of 16 to $64 \mu \mathrm{g} / \mathrm{ml}$ against $S$. aureus which is significant as it is less than $100 \mu \mathrm{g} / \mathrm{ml}$. Quercetin-3-O- $\beta$-D-glucopyranoside also has an EC50 of $1.42 \mu \mathrm{g} / \mathrm{ml}$ and a TEAC of $89.76 \mu \mathrm{g} / \mathrm{ml}$ [56]. Maytenus was initially studied for maytansine, an excessively cytotoxic antileukemic, single macrocyclic ring compound. Semisynthetic and natural two macrocyclic ring Maytansinoids are under development for colon cancer treatment [56].

Isoflavones: Like lignans, isoflavones are also phytoestrogens [43]. Daidzein, genistein, and kievitone have structural similarities to $17 \beta$ estradiol (E2). Daidzein, genistein, and kievitone elevate sex hormonebinding globulin (SHBG), are anti-oxidants, apoptotic, and inhibit angiogenesis, topoisomerase, tyrosine kinase, EGFR, IGFR-1 and NF$\kappa \mathrm{B}$ signaling pathways $[26,43,58]$. Genistein and other isoflavones preferentially bind the anti-proliferative estrogen receptor $\beta$ (ER- $\beta$ ), functioning as SERMs, potentially balancing estrogen receptor $\alpha$ (ERa)'s hyperproliferative effects in adipose tissue, the bone, breast, liver, ovarian thecal cells, prostate, and uterus [59].

Lignans: Lignans are also phytoestrogens. Lignans are derived from berries, flaxseed, sesame seed, whole grains [43]. Matairesinol and secoisolariciresinol are weak estrogen agonists, elevate SHBG, and inhibit aromatase [26]. Like the isoflavone phytoestrogen genistein, the lignin metabolite, enterolactone, is a dose dependent agonistantagonist cancer specific modulator [43].

Polyphenols: Polyphenols are antioxidants. Polyphenols affect cancer by inhibiting cyclooxygenase, DNA topoisomerase, and DNA methylation, inducing phase II detoxification, and influencing cell signaling [25,26]. Polyphenols include cocoa, curcumin (found in turmeric), rice bran oil phenolics, caffeic acid, ferulic acid, and ferulic acid esters [45].

Quinones: Thymoquinone and dithymoquinone are derived from Nigella sativa L. seed (blackseed) [60]. Nigella sativa was the biblical and the prophet Mohammed's curative black cumin, Hippocrates and Doscorides' Melanthion [60,61]. Nigella sativa is also used in Ayurveda and TCM [61]. Nigella sativa seed methanolic extract inhibition of Erlich ascites carcinoma in mice led to patenting of thymoquinone and dithymoquinone for additional research [60]. Thymoquinone and dithymoquinone displayed in vivo cytotoxicity to multidrug resistant cells [60]. Thymoquinone has cytotoxic activity against MCF-7/ Doxorubicin via PTEN, p53, and p21 upregulation; NF- $\kappa \beta$, PI3K-Akt, phase I enzymes, and PPAR inhibition, and phase II enzyme (GST and $\mathrm{N}$-acetyl transferase) activation [61]. Thymoquinone induces caspace-3 apoptosis against Hep-2 cells, whereas caspace-3, -8, and -9 are activated against HL60 p53-myeloid leukemia [61]. Thymoquinone inhibits COX2, which affects breast, lung, stomach, and pancreatic cancers [61]. Thymoquinone inhibits MMPs and VEGF and induces apoptosis via Bak-Bax induction and Bcl-2 and Bcl-XL inhibition [61].
Thymoquinone is also active against bladder, colon, bone, and skin cancers [61].

The Plumbago (leadwort), Drosera (sundews), Nepenthes (monkey cups or tropical pitcher plants), and Juglans nigra (black walnut drupe) derived quinone plumbagin and the Ardisia elliptica (shoebutton ardisia) derived rapanone are under investigation as chemotherapeutics [41]. In vitro, plumbagin has an IC50 less than 10 $\mu \mathrm{M}$ against $\mathrm{A} 549(1.14 \pm 0.02 \mu \mathrm{M}), \mathrm{Caco}_{2}$ colorectal adenocarcinoma $(0.07 \pm 0.01 \mu \mathrm{M})$, DLD-1 human colon adenocarcinoma cells $(0.98 \pm$ $0.11 \mu \mathrm{M})$, HepG2, MCF-7 $(0.06 \pm 0.01 \mu \mathrm{M})$, and SPC212 mesothelioma cell lines $(0.27 \pm 0.01 \mu \mathrm{M})$ (Kuete et al., 2016) [41]. Of these, plumbagin shows greater cytotoxicity than doxorubicin against Caco-2 $(0.72 \pm 0.13 \mu \mathrm{M})$ and MCF-7 $(0.35 \pm 0.05 \mu \mathrm{M})$ [41]. Plumbagin had previously shown good cytotoxicity against Caski, Colo-38, HeLa, MiaPaCa-2, PF-382 leukemia T-cells, and U87MG glioblastomaastrocytoma cell lines [41]. Rapanone achieved an IC50 of $2.27 \pm 1.52$ $\mu \mathrm{M}$ against SPC212 cells, $46.62 \mu \mathrm{M}$ against DLD- 1 cells [41].

Stilbenes: Resveratol, a berry, grape, and peanut derived polyphenol with stilbene derivates, upregulates cancer cell line wild-type p53 $[43,62]$. Rhapoantigenin, a synthetic stilbene derivative of resveratrol, which also degrades HIF-1 $\alpha$ (thereby suppressing VEGF and MAPK), has shown greater anti-angiogensis effect than resveratrol [43]. Stilbenes also activate forkhead box (FOX) O apoptosis transcription factors, while inhibiting Akt, IGF1, the PI3K-Akt and Ras-MEK pathways [43].

Tannins: Fruits' astringency may derive from tannins [47]. Plant derived tannins are subdivided into hydrolysable tannins that are ellagic acid or gallic acid esters and condensed, non-hydrolysable tannins that are oligo- or polymeric proanthocyanidins [47]. Brown algae derived tannins are a separate class, phlorotannins. Tannins may have 12 or more hydroxyl groups and five or more phyenyl groups. Gallic acid and flavan-3-ols may be classified as pseudo tannins. Condensed, non-hydrolysable tannins, which include flavan-3-ols are also classified as flavanols, in which category catechins were mentioned above.

Hydrolysable or pyrogallol-type tannins: Punicalagin, ellagic acid, punicalin are ellagitannins, while gallagic acid is a gallotannin. Carob pods have $0.95 \mathrm{mg} / \mathrm{gm}$ of hydrolysable tannins, while carob fruit have $0.237 \mathrm{mg} / \mathrm{gm}$ to $1.647 \mathrm{mg} / \mathrm{gm}$ of gallic acids, which is the third highest gallic acid content after chestnuts and cloves [47]. Carob fruit fiber contains at least three sets of gallic acid based tannins: Epigallocatechin with four gallic acid units, hexose with two to five gallic acid units, and pentoses with two gallic acid units [47]. Carob fruit fiber also contains prodelphinidin dimer and trimer [47].

Syzygium cumini (Indian blackberry) or Eugenia jambolana, and Phyllanthus emblica or Emblica officinalis (Indian gooseberry, one of the three fruits from which Ayurvedic triphala is made) contain ellagic acid and gallic acid [63]. Indian gooseberry also contains the ellagitannins chebulagic acid, corilagin, emblicanin (also found in Amla), furosin, geraniin, isocorilagin (the $\alpha$-anomer of corilagin), and pyrogallol (also found in chestnut and oak bark) [63]. Chebulagic, ellagic, and gallic acids, and corilagin inhibit NF- $\kappa \beta$ [63]. Corilagin is apoptotic to SKOv3ip, Hey, and HO-8910PM ovarian cancer cell line by inducing G2/M phase arrest and TGF- $\beta / \mathrm{Akt} / \mathrm{Erk} / \mathrm{Smad}$ modulation [63]. Cdc2, Cdk2, Cdk4, Cdk6, cyclin B1 and E inhibition by gallic acid is pro-apoptotic [63].

Punicalagin, derived from Punica granatum (pomengranate) is metabolized to ellagic acid [64]. Pomengranate tannins have 
antiaromatase actitivity against MCF-7 cells that have been transfected with the aromatase gene [64]. Punicalagin, ellagic acid, and total pomengranate tannin are apoptotic to HT-29 cells [64]. Punicalagin and total pomengranate tannin inhibit NF- $\kappa \beta$ response element binding and TNF- $\alpha$ mediated COX-2 expression [64]. Punicalagin is apoptotic to U87MG cells via PARP breakage and caspase-3 and -9 activation [64]. Punicalagin also triggers autophagy cell death in U87MG cells by increasing AMPK-p27 [64].

Condensed or Non-hydrolysable tannins: Proanthocyanidins including flavan-3-ol groups and their galloyl esters form $2.75 \mathrm{mg} / \mathrm{gm}$ of carob pods [47]. Litchi contains proanthocyanidins A1, A2, and A6, and procyanidins B2 and B4 [63]. Proanthocyanidins are polymeric tannins that are depolymerized to anthocyanidins.

Xanthones: Pericarps of Garcinia mangostana (Mangosteen Linn fruit) contain $\alpha$-Mangostin and gartanin $[65,66]$. $\alpha$-Mangostin has anticancer and chemosensitizing activity to melanoma and pancreatic cancer [66]. a-Mangostin has dose dependent anticancer activity against A549 cells via ROS-mediated apoptosis induction, but these effects are negated by $\mathrm{N}$-acetyl cysteine [66]. a-Mangostin dose dependently increases the $\mathrm{Bax} / \mathrm{Bcl}-2$ ratio, inhibits A549 cell migration, down regulates A549 antioxidants - catalase, glutathione peroxidase, and GSH [66]. Gartanin is dose dependently antiproliferative to T98G glioma cells via $\mathrm{PI} 3 \mathrm{~K} / \mathrm{Akt} / \mathrm{mTOR}$ signaling pathway autophagy modulated G1 cell cycle arrest [65]. Garatanin is anti-migratory to T98G cells via MAPK signaling pathway suppression of MMP-2 and -2 [65].

Phytic Acids: Phytic acids include defatted rice bran phytate and inositols [45]. Inositols include inositol phophates, inositol hexakisphosphate (InsP6), and myo-Inositol [67]. Cereals, legumes, and oilseeds yield InsP6, which is broken down to myo-Inositol and inositol phosphates [67]. Inositol hexaphosphate inhibits proliferation [26]. Inositols inhibit cell cycles by inhibiting $\mathrm{pRB}$ phosphorylation and increasing $\mathrm{pRB} / \mathrm{E} 2 \mathrm{~F}$ complex formation [67]. Inositols reduce PI3K, disrupt FGF receptor binding and EGF-transduction, down regulate Akt and Erk, inhibit NF- $\kappa \beta$, and decrease COX2 and PGE2 expression [67]. Inositols impair $\beta$-catenin translocation, $\mathrm{N}$-cadherin, Notch-1, SNAI1 release, and Wnt-activation [67]. Inositols inhibit MMPs and ROCK1/2 release, decrease cofilin and fascin, upregulate focal adhesion kinase (FAK) and e-cadherin, impairing invasiveness and contributing to cancer microenvironment alterations [67]. DU145 tumors are reduced almost $64 \%$ by InsP6 [67].

Phytosterols: Lettuce, nuts, capers, flaxseed, cucumbers, rice bran are phytosterol sources. Stigmasterol is a soy-lipid derived phytosterol, and campesterol is a saw palmetto derived phytosterol [45]. $\beta$ Sitosterol does not stimulate the endometrium, nor do plant stanols and stanol esters stimulate ER-positive MCF-7 [68]. $\beta$-Sitosterol may be most biologically active with liposomal delivery [68]. $\beta$-Sitosterol down regulates NF- $\kappa \beta$, thereby sensitizing cancer cells to TNF- $\alpha$ induced apoptosis [68]. $\beta$-Sitosterol reduces MDA-MB-231 triple negative breast cancer (TNBC) and MCF-7 tumors by $66 \%$ and $87 \%$ respectively, and low density lipoprotein by $8.8 \%$ [68]. $\beta$-Sitosterol's activity against MDA-MB-231 is significant as although TNBC comprises only $15 \%$ of breast cancer, TNBC is treatment resistant, being unresponsive to endocrine and other targeted treatments [69]. $\beta$ Sitosterol and lupeol are the main anticancer constituents of Nardostachys jatamansi DC, a traditional Himalayan medicine herb used for cancer treatment [70].
Terpenes: Terpenes are single or multiple hydrocarbon compounds, categorized as saponins, and mono- or higher terpenoids, including tetraterpenes, based on the number of carbon atoms and isoprene residues [25].

Saponins: Saponins are antioxidants, immune modulators, and cell proliferation regulators $[25,26]$. Saponins are found in legumes and ginseng [26].

Betulinic acid: Betulinic acid from Betula alba (birch) bark, a plant triterpenoid saponin is a known chemopreventive, antiviral, antiinflammatory, and antioxidant [71]. Betulinic acid increases IL-2, TNF- $\alpha$, and CD4+ lymphocyte subsets. Betulinic acid increases the $\mathrm{CD} 4+: \mathrm{CD} 8+$ ratio in a dose dependent manner. Betulinic acid dosed at $200 \mathrm{mg} / \mathrm{kg}$ decreased B-cell lymphoma $2(\mathrm{Bcl}-2)$ protein and cell proliferation marker (Ki-67) protein expression and increased caspase-8 protein expression more than did $25 \mathrm{mg} / \mathrm{kg}$ cyclophosphamide, $\mathrm{p}<0.05$ [72].

Escin: Escin from Aesculus hippocastanum (horse chestnuts) inhibits extracellular signal regulated kinase (ERK) and p38 mitogenactivated protein kinase (MAPK) cell proliferation, motility, and apoptosis pathways for anti-angiogenic endothelial cell migration and motility inhibition [43]. Crude ethyl acetate and methanol extracts of Mangifera pajang (bambangan, a noncommercial mango) kernel, have strong to moderate cytotoxic activity against the HT-29 colon cancer cell line at IC50 of $10 \mu \mathrm{g} / \mathrm{ml}$ [72]. Crude petroleum ether and chloroform extracts of M. pajang stem bark have strong activity at 15 $\mu \mathrm{g} / \mathrm{ml}$ [72]. A component flavonol glycoside, quercitrin had very strong cytotoxic activity against HT-29 at IC50 of $3.82 \pm 0.91 \mu \mathrm{g} / \mathrm{ml}$ [72].

Tripterine: Tripterine, the major active component of Trypterigium wilfordii (thunder duke vine), should be anti-angiogenic and cytotoxic due to modulation of MMP-9, intercellular adhesion molecule (ICAM)-1, vascular endothelial growth factor (VEGF), cell survival inhibitor of apoptosis protein (IAP)-1, X-linked (X)-IAP, Bcl-2, Bcl-xL, flice inhibitory protein (cFLIP), survivin and cell proliferation molecules (cyclin D1, COX-2) in tumor cells [43]. At doses 500-fold higher than its anti-angiogenic activity, withaferin A from Withania somnifera (ashwagandha, Indian ginseng), has demonstrated direct anti-tumor activity in breast, pancreatic, and prostate cancers $[43,73]$.

Monoterpenoids: Monoterpenoids induce apoptosis, cell differentiation, and phase I and II detoxification enzymes, including GST, affect cellular energy, and inhibit cell proliferation $[25,26]$. Monoterpenoids include limonene found in cardamom and Perillyl alcohol derived from the essential oils of lavandin, peppermint, spearmint, cherries and celery seeds. Ferula species derived umbelliprenin inhibits MMPs, but only has greater anti-tumor activity than cisplatin against M4Beu melanoma, and is ineffective against A549, DLD-1, MCF-7, PA1 paclitaxel-sensitive ovarian cancer, and PC3 prostate cancer cell lines [74]. Similarly, F. gummosa derived sesquiterpene coumarin feselol has anti-tumor activity against U937 but not M14, MCF-7, T98G, A549, Saos-2, and FRO cell lines [74].

Diterpenoids: In gallbladder cancer, the diterpenoid oridonin derived from anti-angiogenic Rabdosia rubescens (Dong Ling Cao), activates caspase- 3 and 9 mitochondrial pathway apoptosis, activates PARP1 cleavage, increases the $\mathrm{Bax} / \mathrm{Bcl}-2$ ratio, and inhibits NF- $\kappa \beta$ nuclear translocation [69,75]. In acute lymphoblastic leukemia, oridonin inhibits the Akt-mTOR and Raf-MEK-Erk pathways, but in in vitro human osteosarcoma cells shows Akt and MAPK inhibition [69]. Oridonin treated murine L929 fibrosarcoma cells indicate Erk- 
p53 activation leading to G2/M phase cell cycle arrest [69]. GSH induction by coffee-derived compounds including Kahweol palmitate, a diterpene ester, inhibits DMBA model breast cancer initiation [26].

Tetraterpenes: Carotenoids are anti-oxidant tetraterpenes [25]. $\beta$ carotene found in apricots, carrot, pumpkins, sweet potato is also antiangiogenic, antiproliferative, and induces cellular differentiation [26]. Astaxanthin, $\beta$-carotene, cryptoxanthin, lycopene, lutein, and zeaxanthin have breast cancer animal model anti-cancer activity [43]. Lycopene is found in tomatoes and watermelon, lutein and zeaxanthin are found in broccoli, cayenne and red pepper, corn, leafy greens (collard, kale, romaine lettuce, spinach, and turnip), paprika, and peas [76].

\section{A Combination Herbal}

Yangzheng xiaoji, a 16 herb TCM dose dependently inhibits adhesion of A549, MCF-7, HRT18 colorectal cancer cells, HGC27 gastric cancer cells, and MG-63 osteosarcoma cells via the P13K pathway and anti-angiogenesis [77]. The Yangzheng xiaoji extract DME25 inhibits cancer growth by inhibiting FAK pathway phosphorylation [77].

\section{Whole Plant Nutraceuticals}

\section{Cardamon}

In female Swiss albino mice, cardamom, garlic, and saffron are chemoprotective against DMBA induced skin cancer [28]. Cardamon stimulates phase II detoxification and anti-oxidation in female Swiss albino mice with DMBA treated skin and livers [28]. Cardamom contains numerous phytochemicals, some of which are mentioned below. Phase I trials of limonene, a major constituent of cardamom suggest breast, colorectal, and prostate cancer inhibition with minimal toxicity at doses up to $100 \mathrm{mg} / \mathrm{kg}$ [28]. D-Limonene is metabolized to perillyl alcohol, which inhibits G-protein isoprenylation [26]. DLimonene inhibits gastric and lung cancers and leukemia [28]. 1,8cineole inhibits and induces apoptosis in SK-MEL-28 human melanoma cells, B16-F1 murine melanoma cells, and Molt 4B and HL-60 human leukemia cells [28]. Linalool uses p53 upregulation against leukemia, and inhibits renal adenocarcinoma and amelanotic melanoma [28]. $\alpha$-Pinene and $\alpha$-Terpineol are anti-inflammatory to oral buccal cells [28]. Myrcene is chemoprotective against DMPA in rats, and apoptotic in human hepatoma cell lines. Trans-nerolidol is cytotoxic to A-549 human lung carcinoma cells and DLD-1 cells [28].

Artemisia capillaris (wormwood), which is known to inhibit CNE-2 nasopharyngeal carcinoma, DMBA induced breast cancer, SMMC-7721 human hepatoma, HL-60 leukemia, HepG2, Huh-7 human liver cells, HeLa cervical cancer, and mouse liver cells, contains borneol, which is also a constituent of cardamom [28,78]. Borneol is anti-oxidative, cytotoxic, DNA-damaging, and DNA-protective to Caco-2 and VH10 [28].

\section{Marine compounds}

Ecteinascidia turbinata, the source of the active ingredient of Trabectedin, approved for the treatment of platinum-sensitive ovarian cancer and tumor soft tissue sarcoma, displays in vitro and in vivo transcription factor inhibition [79]. Elysia rufescens derived Kahalalide $F$, is the basis for synthetic PM02734, which is in Phase II clinical trials for evaluation of H322 and A549 cell line apoptosis [79]. Kahalalide F inhibited breast, liver, and pancreatic cancer, as well as melanoma in Phase I trials. Spisula polynyma derived ES-285-HC1 has inhibited solid hepatocellular, prostate, and renal cancer in vivo [79]. Dicathais orbita containing the indole derivatives tyrindoleninone, tyrindolinone, 6-bromoisatin and 6,6'-dibromoindirubin, demonstrated in vivo apoptotic activity against azoxymethane exposed rat distal colon cells [79]. Dicathais orbita derived tyrindoleninone and 6-bromoisatin are twice as apoptotic to the KGN tumor-derived granulosa cell line than to normal primary human granulosa cells (HGC), 66\% to $31 \%$, respectively [79]. The biological plausibility of 6 bromoisatin containing compounds will be presented in a separate article on oncologic homeopathic remedies.

\section{Effect on Breast, Cervical, and Ovarian Cancers}

As known nutraceutical inhibition of endometrial cancer focuses on I3C, this section focuses on breast, cervical, and ovarian cancers [26].

\section{Breast cancer}

Breast cancer inhibitors include allium derivatives, $\beta$-carotene and other carotenoids, catechin, coumarin, curcumin, dithiolthiones, dried green coffee, fiber, glucosinolates and indoles (DIM and I3C), dLimonene, isoflavones and lignans, glycirrhizic acid, kahweol palmitate, orange oil, protease inhibitors/Bowman-Birk inhibitor (BBI), rosemary extract, and selenium/organoselenium compounds $[26,80]$. Actual annual integrative cancer treatment costs for an early stage breast cancer patient are USD 1,594 [81]. An idealized integrative treatment program for stage 4 breast cancer that includes bromelain, coenzyme Q10, curcumin, green tea, intravenous artesunate and ascorbic acid, melatonin, mistletoe injections, Trametes versicolor mushroom, vitamin D3, and Wobenzyme TM digestive enzymes has an annual total cost of USD 27,137.16 [81].

In murine studies BITC has proven MCF7 and HBL-100 inhibition by $\mathrm{p} 53-\mathrm{LKB} 1$ and $\mathrm{p} 73-\mathrm{LKB} 1$ pathway activation, which enhances $\mathrm{p} 53$ signaling [82]. As LKB1 activation is associated with improved breast cancer outcomes this finding is significant [82]. BITC increases breast cancer cell p53, Erk, and cyclic adenine monophosphate-responseelement-binding protein (CREB) phosphorylation, but decreases Akt phosphorylation [82]. In vitro studies against MDA-MB-231, MDAMB-468, BT474, T47D, Hs578t, HCT116p53-/-, and HCT116p53+/+ cells show BITC induced p53-independent apoptosis [82].

Bitter gourd derived triterpenoids have demonstrated moderate cytotoxicity to MCF-7 and MDA-MB-231 breast cancer cells, IC50 of 19 and $23 \mathrm{M}$ respectively at 72 hours [83]. Bitter gourd derived triterpenoids have several mechanisms of action. In some cases, caspase-dependent apoptosis occurs [83]. Akt-NF- $\kappa B$ signaling is down-regulated, p38 mitogen activated protein kinase and p53 are upregulated, ROS generation and cytoprotective autophagy are increased, and histone deacetylases (HDACs) protein expression is decreased [83]. In other cases, apoptotic peroxisome proliferator-activated receptor (PPAR) $\gamma$-targeted gene products' modulation occurs [83].

Caffeic acid phenethyl ester from propolis, which is from floral resins of buds and sprouts of green trees that is collected by bees, has dose and time dependent strong cytotoxicity against MDA-MB-231, IC50 of $14.08 \mu \mathrm{M}$ and excellent cytotoxicity against Hs578T, IC50 of $8.01 \mu \mathrm{M}$ [84]. Caffeic acid phenethyl ester is caspase-3 dependent apoptotic and anti-proliferative by NF- $\kappa \beta$ inhibition, which also increases the Bax: Bcl-2 ratio [84]. Cephalotaxus griffithii Hook. F. (Griffith's plum yew) needle derived flavonoids via petroleum ether 
Page 8 of 12

extraction are moderately cytotoxic to ZR751 breast cancer cells, IC50 $22.3 \pm 3.9 \mu \mathrm{g} / \mathrm{ml}[85]$. Curcumin and sulforaphane, also modulate HDACs for breast cancer antiproliferation [83]. The ML-1 lectin containing mistletoe extracts Iscador $\mathrm{M}$ special and Iscador $\mathrm{Qu}$, dosed at $15 \mathrm{~g} / \mathrm{dl}$ have strong cytotoxic activity to the MAXF-401-NL breast cancer line [80].

In murine studies, CYD-6-28, a synthetic analog of oridonin, a diterpenoid terpene, dosed at $5 \mathrm{mg} / \mathrm{kg}$, inhibited TNBC cell lines HCC1806 and HCC1937 [69]. CYD-6-28 induces Erk, p21, caspase-3, $-7,-8$ and PARP cleavage, G2/M-phase cell cycle arrest, and death receptor 5 (DR5) mediated apoptosis [69]. CYD-6-28 inhibits Akt, cyclin D1, FLIPL, STAT3, and XIAP [69]. CYD-6-28's efficacy may be due to improved aqueous solubility and cell permeability from a thiazole ring at A-ring C-1 and C-2 [69].

Edible Phaleria macrocarpa (Scheff.) Boerl fruit (mahkota dewa) of Indonesian traditional medicine has flavonoid, flavonol, phenol, saponin, and terpenoid derivatives [86]. Ethyl acetate and methanol extracts have strong cytotoxicity comparable to standard gallic acid, with IC50 $8.15 \pm 0.02 \mathrm{~g} / \mathrm{ml}$ in DPPH antioxidant assay [86]. Gallic acid is cytotoxic to brain, breast, cervix, colon, esophageal, and gastric cancer cell lines [86]. The chloroform extract has excellent cytotoxicity against MDA-MB-231 breast cancer cells, IC50 $7.80 \pm 1.57 \mu \mathrm{g} / \mathrm{ml}$ at 48 hours [86]. The $P$. macrocarpa hexane extract has excellent cytotoxicity against MDA-MB-231, IC50 $4.6 \pm 1.32 \mu \mathrm{g} / \mathrm{ml}$ at 48 hours, while the ethyl acetate extract has good cytotoxicity against MDA-MB231, IC50 $6.4 \pm 1.09 \mu \mathrm{g} / \mathrm{ml}$ at 48 hours [86]. Ethanolic mango seed extract may be apoptotic to MCF-7 cells via ROS induction [87]. Ethanolic kernel extract of Mangifera indica L. (waterlily mango) has dose dependent strong cytotoxicity to MCF-7, IC50 $15.6 \mu \mathrm{g} / \mathrm{ml}$, moderate cytotoxicity to MDA-MB-231, IC50 $31.25 \mu \mathrm{g} / \mathrm{ml}$, and insignificant cytotoxicity to MCF-10A, all at 72 hours [88].

In vitro and in vivo mouse studies showed that the flavone, chloroform extracted luteolin from Eclipta alba (Bhringraj) dose and time dependently selectively activates intrinsic apoptosis by releasing mitochondrial apoptogenic proteins into the cytosol, inhibiting caspase-9, up regulating pro-apoptotic molecular chaperone heat shock protein 60 (Hsp60) and down regulating anti-apoptotic protein XIAP in MCF-7 and MDA-MB-231 cells, but spares MCF-10A normal breast epithelial cells [89]. Luteolin was also found to be more active than the twice as available coumarin wedelolactone component of $\mathrm{E}$. alba [89]. Chloroform extracted E. alba luteolin was effective at 50, 100, and $200 \mu \mathrm{g} / \mathrm{ml}$. Future studies should explore the efficacy of lower concentrations.

Nobiletin and tangeretin are dose dependently antiproliferative to MCF-7 and MDA-MB-435 cells via G1 cell cycle phase arrest [51]. Naringin increases p21, modulates the $\beta$-catenin pathway, and induces G1 phase cell cycle arrest, resulting in TNBC apoptosis and antiproliferation [51]. Hesperidin activates caspase-3 and p53 mediated apoptosis against MCF-7 cells [51]. Hesperetin is antiproliferative to MDA-MB-231 cells by GLUT1 and GLUT4 down regulation, and IR- $\beta$ and Akt phosphorylation inhibition, which reduces basal and insulinstimulated glucose uptake [51]. Naringenin inhibits MCF-7 basal and insulin-stimulated glucose uptake via PI3K and MEK inhibition [51]. Hesperetin suppresses in vivo aromatase expression; therefore, it is biologically plausible that hesperetin will be effective against ER+ breast cancers [51]. Hesperetin and naringenin have in vitro activity against HER2 positive cancers, which is biologically plausible as hesperetin and naringenin are HER2 tyrosine kinase inhibitors [51].
The quinones plumbellagiagin and rapanone induce caspase independent, ROS and MMP mediated MCF-7 cell apoptosis [41].

Crude ethyl acetate and methanol extracts of $M$. pajang kernel, and crude petroleum ether and chloroform extracts of the stem bark have strong cytotoxic activity against MCF-7 cells at IC50 of $10 \mu \mathrm{g} / \mathrm{ml}$ and $15 \mu \mathrm{g} / \mathrm{ml}$, respectively [72]. The cycloartane triterpene component, $3 \beta$ hydroxy-cycloart-24-ene-26-oic acid had moderate cytotoxic activity towards MCF-7 at IC50 $13.03 \pm 0.81 \mu \mathrm{g} / \mathrm{ml}$ [72]. Pseuduvaria monticola leaf menthol extracts $(6 \mathrm{E}, 10 \mathrm{E})$ isopolycerasoidol and $(6 \mathrm{E}$, $10 \mathrm{E}$ ) isopolycerasoidol methyl ester are selectively anti-proliferative and cytotoxic to MCF-7 and MDA-MB-231 cells via ROS induced changes to mitochondrial membrane permeability, dose dependent caspase 3,7, and 9 activation, anti-apoptotic Bcl-2 down regulation, and nuclear accumulation of p38 MAPK [90]. At 48 hours, (6E,10E) isopolycerasoidol had IC50 $59 \pm 5.1 \mathrm{M}$ against MCF-7 and IC50 $76 \pm$ 8.5 $\mathrm{M}$ against MDA-MB-231, while (6E,10E) isopolycerasoidol methyl ester is more potent at IC50 $43 \pm 2.4$ against MCF-7 and IC50 $58 \pm 2.6$ against MDA-MB-231 [90]. Normal human breast epithelial MCF-10A cells are comparatively spared with IC50 of $94 \pm 5.9 \mathrm{M}$ for $(6 \mathrm{E}, 10 \mathrm{E})$ isopolycerasoidol, and IC50 $90 \pm 4.7 \mathrm{M}$ for $(6 \mathrm{E}, 10 \mathrm{E})$ isopolycerasoidol methyl ester [90].

Silibinin, the main active flavonoid component of Silymarin, derived from Silibum marianum (milk thistle) seeds, is anti-angiogenic by MMP-2 and capillary formation suppression, and inhibition of angiogenic signaling molecules [43,77]. Silibinin induces caspase cascade apoptosis in TRAIL-resistant cancers, down regulates Aktmediated NF- $\kappa B 1$ [77]. Silibinin inhibits MDA-MB-231 breast cancer cell line metastases by inhibiting mRNA levels of GDP dissociation inhibitor (D4-GDI) expression and cell division cycle 42 [77].

Withaferin $\mathrm{A}$ has numerous mechanisms of action: Inactivation of Akt and NF-kB to achieve apoptosis, decrease in pro-survival protein B-cell lymphoma 2 (Bcl-2), gap-2/mitosis (G2/M) cell cycle arrest, generation of ROS, induction of protease-activated receptor-4 (Par-4), activation of caspase 3 and 9 activities, DNA damage, inhibition of molecular chaperone heat shock protein 90 (HSP90), regulation of forkhead box O 3a (FOXO3a) and Bcl-2 interacting mediator of cell death (Bim), and inhibition of Notch-1 [73,91,92]. For breast cancer inhibition, withaferin A activates the extracellular signal-regulated kinase (ERK)-ribosomal S6 kinase (RSK) and ETS-like transcription factor 1 (Elk1)-C-EBP homologous protein (CHOP) kinase pathways which upregulate DR5 transcription [92]. This mechanism also provides synergism with celecoxib, etoposide, and TRAIL [92].

\section{Cervical Cancer}

Betulinic acid dosed at $100 \mathrm{mg} / \mathrm{kg}$ and $200 \mathrm{mg} / \mathrm{kg}$ showed dose dependent in vivo anti-tumor activity in U14 cervical cancer bearing mice, which approximated to that of $25 \mathrm{mg} / \mathrm{kg}$ cyclophosphamide, $\mathrm{p}$ $<0.05$ [71]. Conium maculatum (hemlock) ethanolic extract is dose and time dependent anti-proliferative via sub-G stage cell cycle arrest by 48 hours [93]. At 24 hours ROS generation is increased. By 48 hours MMP depolarization, phosphatidyl serine externalization, morphological changes, DNA damage, decreased Bcl-2:Bax, and caspase-3 dependent apoptosis occur in HeLa cells [93]. C. maculatum ethanolic extract is also effective against A375, A549, and HepG2 cell lines, with WRL68 normal liver cells surviving treatment better than PBMCs, indicating limited harm to normal tissue [93].

Crude ethyl acetate and methanol extracts of $M$. pajang kernel, and crude petroleum ether and chloroform extracts of the stem bark have 
strong cytotoxic activity against the HeLa cervical cancer cell line at IC50 of $10 \mu \mathrm{g} / \mathrm{ml}$ and $15 \mu \mathrm{g} / \mathrm{ml}$, respectively [72]. 33-hydroxycycloart-24-ene-26-oic acid had strong anti-cancer activity towards MCF-7 cells at IC50 $6.27 \pm 0.61 \mu \mathrm{g} / \mathrm{ml}[72]$. Quercitrin had moderate to strong cytotoxic activity at $11.93 \pm 0.63 \mu \mathrm{g} / \mathrm{ml}$ [72]. Oridonin inhibits the HeLa cell line P13K-Akt pathway [69].

Curcumin and emodin down regulate TGF- $\beta$ receptor II, P-Smad3, and Smad4, which inhibits TGF- induced migration and invasion in HeLa and SiHa cervical cancer cell lines [94]. Curcumin and emodin up regulate the Bax:Bcl-2 ratio which inhibits p15, p16, p21, p27, CDK6, CyclinD1, and Pin1 expression, thereby inhibiting Wnt/ $\beta$ catenin in HeLa cells [94]. SiHa cells were chosen for TGF- $\beta$ resistance [94]. Curcumin and emodin are syngergistic. Curcumin and emodin were dosed at IC50: For curcumin, $15 \mu \mathrm{M}$ in SiHa and $25 \mu \mathrm{M}$ in HeLa cells, representing strong cytotoxicity. For emodin, $40 \mu \mathrm{M}$ in SiHa and HeLa cells [94]. Curcumin and emodin may not be as good candidates for cervical cancer inhibition as $M$. pajang extracts, but, if tolerated, curcumin offers additional overall health benefits, such that curcumin and emodin for chemosensitization should not be overlooked.

The phenol, naringin modulates GM3 ganglioside, affecting EGFR signaling, resulting in HeLa suppression [51]. Taxifolin is synergistic with andrographolide (a diterpenoid lactone) against HeLa cells by reducing andrographolide induced protective autophagy, while increasing mitochondrial outer-membrane permeabilization, caspase dependent, and independent cell death [50].

In vivo athymic nude mice models show that withaferin $\mathrm{A}$, dosed at $8 \mathrm{mg} / \mathrm{kg}$ intraperitoneally on alternate days, can reduce CaSki human papilloma virus (HPV) types 16 and 18 positive, cervical cancer cell line tumors by $70 \%, \mathrm{p}<.01$ at 6 weeks of treatment [73]. The withaferin A derivative, 3-azido Withaferin A (3-azidoWA), irreversibly inhibits MMP-2 via dose dependent pro-apoptotic extracellular par-4 secretion, resulting in suppressed motility and invasion of $\mathrm{HeLa}$ cervical and PC-3 prostate cancer cell lines ( $\mathrm{p}<.01)$ [95]. In vivo mice studies indicate 3 -azidoWA, dosed at $30 \mathrm{mg} / \mathrm{kg} /$ day intraperitoneally, dosed on day 8 or days 8 to 10 , dose dependently activates capase- 3 mediated apoptosis and is dose dependently anti-angiogenic [95]. Withaferin A down regulates human papilloma virus (HPV) E6 and E7 oncoproteins' expression, in turn reactivating p53-dependent tumor suppression [73,91].

\section{Ovarian Cancer}

The 71 and 87 percentage point survival advantages between Stage 1 and Stages IIIC and IV ovarian cancer respectively indicates a need for more effective treatment modalities for advanced stage ovarian cancer and mechanisms for ovarian cancer prevention [62]. However, a brief literature search suggests that much more could be done to find nutraceutical therapies targeted to ovarian cancer treatment.

The P. macrocarpa methanol extract has excellent cytotoxicity against SKOV-3 ovarian cancer cells, IC50 $7.75 \pm 2.56 \mu \mathrm{g} / \mathrm{ml}$ at 72 hours [86]. The $P$. macrocarpa hexane extracts have good cytotoxicity against SKOV-3, IC50 $10.15 \pm 2.71 \mu \mathrm{g} / \mathrm{ml}$ at 24 hours [86]. The P. macrocarpa ethyl acetate extracts have good cytotoxicity against SKOV-3, IC50 $8.1 \pm 1.81 \mu \mathrm{g} / \mathrm{ml}$ at 72 hours [86]. Withaferin A inhibits ovarian adenocarcinoma cell lines $\mathrm{CaOV} 3$ and SKOV3 by down regulating Notch1, Notch3, Cdc25C, total and phosphorylated Akt, and bcl-2 proteins, which in turn induces early apoptosis $(\mathrm{p}<0.05)$ and G2/M phase cell cycle arrest [96].

\section{Future Research}

Research is needed to determine which of the whole plant or organism, the natural phytochemical component, the semi-synthetic phytochemical, or the completely synthetic phytochemical, is the most efficacious form of a nutraceutical. Crude extracts can derive anticancer activity from phytochemical components that are removed with additional processing. This is the case with Ferula extracts that lose phenolic components when purified to terpenoid coumarins [74]. However, components of the whole plant or intact portions of the plant can have antagonistic effects, necessitating separation for maximal beneficial effect. For instance, quercitrin appears to antagonize $M$. pajang from which it is derived [72]. Trials of I3C should evaluate the concentration of the I3C metabolite DIM present following administration and metabolism of I3C [28]. Studies on cineole should determine the equivalence, if any, between 1,4-Cineole, the major phytochemical in cardamom, and 1,8-cineole, the most studied cineole [28]. Similarly, clarity is needed as to the activity of each isomer of limonene. All studies on isomeric phytochemicals should specify the isomer used for clarity, efficacy, and adverse effect ascertainment.

Similarly, delivery modality effectiveness for nutraceuticals displays enormous variation. Improving oral nutraceutical bioavailability is an emerging discipline [97]. While nano-encapsulated EGCG is 10-fold more efficacious than non-encapsulated EGCG, and berberine and curcumin act similarly, kaempferol is significantly less efficacious when encapsulated [43]. Nutraceutical microbial fermentation can improve bioavailability and antioxidant efficacy [45]. Therefore, the optimal delivery modality for each nutraceutical's optimal efficacy should be determined. In this light, quercetin is being studied as an enhancer for green tea polyphenol bioavailability and activity [98]. Pro-drug derivatives may need to be developed [52]. Similarly, with synthetic analogs, bioavailability enhancement may be possible without adverse effects as displayed by CYD-6-28 [69]. Then, the focus can shift to making manufacturers supply pharmaceutical grade nutraceuticals in the most efficacious delivery modality.

In vivo trials of withaferin A for ovarian adenocarcinoma treatment are a logical progression from successful in vitro CaOV3 and SKOV3 cell line studies [96]. Additional trials of $M$. pajang may indicate if a breast, cervix, or colon cancer treatment can be realistically pursued [72]. The P. macrocarpa extracts can be further studied for breast and ovarian cancer [86]. The main cytotoxic constituents of M. indica L.'s ethanolic kernel extract could be determined and studied in vivo [88]. C. maculatum ethanolic extract should undergo in vivo murine trials against A375, A549, HeLa, HepG2, and WRL68 cell lines, to assess efficacy and tolerability. Tangeretin, nobiletin and 5-AcTMF should be further trialed for breast, colon, leukemia, myeloma, and NSCLC treatment [52-54]. BITC should be further studied for breast cancer treatment [82]

Clinical trials of silibinin, Ganoderma lucidum polysaccharides and ganoderic acids, cordycepin from Cordyceps millitaris, EPA, $\gamma$ linolenic acid, Yangzheng Xiaoji and DME25 may lead to antimetastatic drug candidates [77]. Comparative effectiveness trials of EGCG, silibinin, curcumin, melatonin, oleanolic acid, resveratrol, withaferin A, enterolactone, kaempferol, and tripterine, listed from theoretically most anti-angiogenic activity to least anti-angiogenic activity, could determine which of these polyphenol nutraceuticals is the most anti-angiogenic for a given cancer [43]. These nutraceuticals can also be trialed with conventional chemoradiation to determine if synergism will permit chemoradiation dose reduction. 
Page 10 of 12

Nutraceutical treatment of TNBC is worthy of further investigation. $\beta$-Sitosterol, bitter gourd, caffeic acid phenethyl ester from propolis, chloroform extracted luteolin from Eclipta alba, Phaleria macrocarpa chloroform and hexane nobiletin extracts, Pseuduvaria monticola leaf menthol extracts (6E,10E) isopolycerasoidol and $(6 \mathrm{E}, 10 \mathrm{E})$ isopolycerasoidol methyl ester, silibinin, and the tangeretin derivative 5-AcTMF may be potential drug candidates. Microenvironmental efficacy limitations of thymoquinone and its synthetic analogs should be performed to ascertain if microenvironmental effects limit thymoquinone's in vivo efficacy against bladder, bone, breast, lung, stomach, and pancreatic cancer cell lines, in addition to known limitations of thymoquinone in ID8-NGL mouse ovarian cancer [61,99].

\section{Conclusion}

Some nutraceuticals such as the Ferula species derived phytoestrogenic monoterpene umbelliprenin have very limited curative anti-cancer effects that can be limited to a single cancer. Other nutraceuticals, such as the natural MMP inhibitors, 3-azido WA, aqueous cinnamon extract, green tea extract, curcumin, fenugreek derived steroidal saponin, and marine compound derived chitooligosacharides should have a broader applicability. When the incidence and severity of a cancer, for example TNBC is considered, there is benefit in developing a nutraceutical that initially seems to be exclusively of single indication benefit. The breadth and depth of the nutraceutical clinical pharmacology literature suggests that an increased range of curative nutraceutical cancer treatments will become available. However, endometrial cancer treatment should be given as much consideration as have breast, cervical, and ovarian cancers.

\section{References}

1. Schütze T, Längler A, Zuzak TJ, Schmidt P, Zernikow B (2016) Use of complementary and alternative medicine by pediatric oncology patients during palliative care. Support Care Cancer 24: 2869-2875.

2. King N, Balneaves LG, Levin GT, Nguyen T, Nation JG, et al. (2015) Surveys of cancer patients and cancer health care providers regarding complementary therapy use, communication, and information needs. Integr Cancer Ther 14: 515-524.

3. Arora S, Aggarwal A, Singla P, Jyoti S, Tandon S (2013) Anti-proliferative effects of homeopathic medicines on human kidney, colon and breast cancer cells. Homeopathy 102: 274-282.

4. Frenkel M (2015) Is there a role for homeopathy in cancer care? Questions and challenges. Curr Oncol Rep 17: 43.

5. Klafke N, Mahler C, von Hagens C, Rochon J, Schneeweiss A, et al. (2015) A complex nursing intervention of complementary and alternative medicine (CAM) to increase quality of life in patients with breast and gynecologic cancer undergoing chemotherapy: Study protocol for a partially randomized patient preference trial. Trials 16: 1 .

6. Rossi E, Vita A, Baccetti S, Di Stefano M, Voller F, et al. (2015) Complementary and alternative medicine for cancer patients: Results of the EPAAC survey on integrative oncology centres in Europe. Support Care Cancer 23: 1795-1806.

7. Münstedt K, Maisch M, Tinneberg HR, Hübner J (2014) Complementary and alternative medicine (CAM) in obstetrics and gynaecology: A survey of office-based obstetricians and gynaecologists regarding attitudes towards CAM, its provision and cooperation with other CAM providers in the state of Hesse, Germany. Arch of Gynecol Obstet 290: 1133-1139.

8. Wanchai A, Armer JM, Stewart BR (2010) Breast cancer survivors' perspectives of care practices in Western and alternative medicine. Oncol Nurs Forum 37: 494-500.
9. Saghatchian M, Bihan C, Chenailler C, Mazouni C, Dauchy S, et al. (2014) Exploring frontiers: Use of complementary and alternative medicine among patients with early-stage breast cancer. The Breast 23: 279-285.

10. Singendonk M, Kaspers GJ, Naafs-Wilstra M, Schouten-van Meeteren A, Loeffen J, et al. (2013) High prevalence of complementary and alternative medicine use in the Dutch pediatric oncology population: A multicenter survey. Eur J Pediatr 172: 31-37.

11. Garland SN, Valentine D, Desai K, Li S, Langer C, et al. (2013) Complementary and alternative medicine use and benefit finding among cancer patients. J Altern Complement Med 19: 876-881.

12. Bonacchi A, Fazzi L, Toccafondi A, Cantore M, Mambrini A, et al. (2014) Use and perceived benefits of complementary therapies by cancer patients receiving conventional treatment in Italy. J Pain Symptom Manage 47: 26-34.

13. Schmitt J, Ferro A (2013) Nutraceuticals: Is there good science behind the hype? Br J Clin Pharmacol 75: 585-587.

14. Friedel WE, Matthes H, Bock PR, Zänker KS (2009) Systematic evaluation of the protocols and long-term mistletoe application in nonmetastatic colorectal carcinoma: clinical effects of supportive mistletoe treatment within chemo and/or radiotherapy multicenter, controlled, observational cohort study. J Soc Integr Oncol 7: 137-145.

15. George DR, Edris W, Hanson R, Gilman F (2016) Medicinal plants the next generation. Lancet 387: 220-221.

16. Yuan H, Ma Q, Ye L, Piao G (2016) The traditional medicine and modern medicine from natural products. Molecules 21: 559

17. Seppo (2017) Hack your tea-how to get 5 times more out of a cup of green tea. AcneEinstein.com

18. Chen L, Mo H, Zhao L, Gao W, Wang S, et al. (2017) Therapeutic properties of green tea against environmental insults. J Nutr Biochem 40: $1-13$.

19. Andrews GR, Roberts SC (2017) Bioprocess engineering of plant cell suspension cultures. Appl Bioeng 12: 5 .

20. Bagchi D (2008) Nutraceutical and functional food regulations in the United States and around the world. Academic Press, Burlington.

21. Drake PM, Szeto TH, Paul MJ, Teh AY, Ma JK (2017) Recombinant biologic products versus nutraceuticals from plants-a regulatory choice? Br J Clin Pharmacol 83: 82-87.

22. Minuz P, Velo G, Violi F, Ferro A (2017) Are nutraceuticals the modern panacea? From myth to science. Br J Clin Pharmacol 83: 5-7.

23. Tariq AL, Reyaz AL (2012) Phytochemical analysis of Camellia sinensis Leaves. Int J Drug Dev \& Res 4: 311-316.

24. Buckingham J, Baggaley KH, Roberts AD, Szabó LF (2010) Dictionary of alkaloids, 2nd edition. CRC Press, Taylor \& Francis Group, Boca Raton, FL, USA.

25. Rais J, Jafri A, Siddiqui S, Tripathi M, Arshad M (2017) Phytochemicals in the treatment of ovarian cancer. Front Biosci (Elite Ed) 9: 67-75.

26. Cline JM, Hughes CL (1998) Phytochemicals for the prevention of breast and endometrial cancer. In Foon KA, Muss HB (eds), Biological and Hormonal Therapies of Cancer, Kluwer Academic Publishers Boston, USA.

27. Sun Y, Guo M, Feng Y, Zheng H, Lei P, et al. (2016) Effect of ginseng polysaccharides on NK cell cytotoxicity in immunosuppressed mice. Exp Ther Med 12: 3773-3777.

28. Acharya A, Das I, Singh S, Saha T (2010) Chemopreventive properties of indole-3-carbinol, diindolylmethane and other constituents of cardamom against carcinogensis. Recent Pat Food Nutr Agric 2: 166-177.

29. Arshad MS, Sohaib M, Nadeem M, Saeed F, Imran A, et al. (2017) Status and trends of nutraceuticals from onion and onion by-products: A critical review. Cogent Food Agric 3: 1280254.

30. Zeng Y, Li Y, Yang J, Pu X, Du J, et al. (2017) Therapeutic role of functional components in alliums for preventive chronic disease in human being. Evid Based Complement Alternat Med 2017: 9402849. 
31. Zhong WL, Qin Y, Chen S, Sun T (2017) Antitumor effect of natural product molecules against lung cancer. In a global scientific visionprevention, diagnosis, and treatment of lung cancer. InTech, Rijeka.

32. Gliszczynska A, Niezgoda N, Gladkowski W, Switalska M, Wietrzyk J (2017) Isoprenoid-phospholipid conjugates as potential therapeutic agents: Synthesis, characterization and antiproliferative studies. PloS ONE.12: $\mathrm{e} 0172238$.

33. Liu W, Xu X, Zhang R, Cheng T, Cao Y, et al. (2016) Engineering Escherichia coli for high-yield geraniol production with biotransformation of geranyl acetate to geraniol under fed-batch culture. Biotechnol Biofuels 9: 58 .

34. Tippmann S, Ferreira R, Siewers V, Nielsen J, Chen Y (2017) Effects of acetoacetyl-CoA synthase expression on production of farnesene in Saccharomyces cerevisiae. J Ind Microbiol Biotechnol 9: 1-2.

35. Varker KA, Ansel A, Aukerman G, Carson WE (2012) Review of complementary and alternative medicine and selected nutraceuticals: Background for a pilot study on nutrigenomic intervention in patients with advanced cancer. Alternate Therapies Health Med, 18: 26-34.

36. Sun Y, Jia X, Hou L, Liu X, Gao Q (2017) Involvement of apoptotic pathways in docosahexaenoic acid-induced benefit in prostate cancer: Pathway-focused gene expression analysis using RT 2 Profile PCR Array System. Lipids Health Dis 16: 59.

37. Yarnell E, Abascal K (2009) Plant coumarins: Myths and realities. Alternative and Complementary Therapies 15: 24-30.

38. Wang YH, Avula B, Nanayakkara NP, Zhao J, Khan IA (2013) Cassia cinnamon as a source of coumarin in cinnamon-flavored food and food supplements in the United States. J Agric Food Chem 61: 4470-4476.

39. Morsy SA, Farahat AA, Nasr MNA, Tantawy AS (2017) Synthesis, molecular modeling and anticancer activity of new coumarin containing compounds. Saudi Pharm J In press.

40. Dandriyal J, Singla R, Kumar M, Jaitak V (2016) Recent developments of C-4 substituted coumarin derivatives as anticancer agents. Eur J Med Chem 119: 141-168.

41. Kuete V, Omosa LK, Tala VRS, Midiwo JO, Mbaveng AT, et al. (2016) Cytotoxicity of Plumbagin, Rapanone and 12 other naturally occurring Quinones from Kenyan Flora towards human carcinoma cells. BMC Pharmacol Toxicol 17: 60.

42. Alam M, Khan A, Wadoo A, Khan A, Bashir S, et al. (2016) Bioassayguided isolation of sesquiterpene coumarins from ferula narthex bioss: A new anticancer agent. Front Pharmacol 7: 26.

43. Wang Z, Dabrosin C, Yin X, Fuster MM, Arreola A, et al. (2015) Broad targeting of angiogenesis for cancer prevention and therapy. Semin Cancer Biol: S224-S243.

44. Freyer G, You B, Villet S, Tartas S, Fournel-Federico C, et al. (2014) Openlabel uncontrolled pilot study to evaluate complementary therapy with Ruta graveolens $9 \mathrm{c}$ in patients with advanced cancer. Homeopathy, 103: 232-238.

45. Henderson AJ, Ollila CA, Kumar A, Borresen EC, Raina K, et al. (2012) Chemopreventive properties of dietary rice bran: Current status and future prospects. Advanced Nutrition 3: 643-653.

46. Aiyer HS, Warri AM, Woode DR, Hilakivi-Clarke L, Clarke R (2012) Influence of berry-polyphenols on receptor signaling and cell-death pathways: Implications for breast cancer prevention. J Agric Food Chem 60: 5693-5708.

47. Goulas V, Stylos E, Chatziathanasiadou MV, Mavromoustakos T, Tzakos A (2016) Functional components of carob fruit: Linking the chemical and biological space. Int J Mol Sci 17: 1875.

48. Sorrenti V, Vanella L, Acquaviva R, Cardile V, Giofrè S, et al. (2015) Cyanidin induces apoptosis and differentiation in prostate cancer cells. Int J Oncol 47: 1303-1310.

49. Raúl SC, Beatriz HC, Joseoziel LG, Francenia SSN (2017) Phenolic compounds in genus Smilax (Sarsaparilla). In M Soto-Hernandez, M Palma-Tenango, $M$ del Roasario Garcia-Mateos, Eds., Phenolic compounds - Natural sources, importance and applications. Intech, Rijeka.
50. Alzaharna M, Alqouqa I, Cheung HY (2017) Taxifolin synergizes Andrographolide-induced cell death by attenuation of autophagy and augmentation of caspase dependent and independent cell death in HeLa cells. PLoS One 12: e0171325.

51. Yi L, Ma S, Ren D (2017) Phytochemistry and bioactivity of Citrus flavonoids: a focus on antioxidant, anti-inflammatory, anticancer and cardiovascular protection activities. Phytochem Rev 2017: 1-33.

52. Li YR, Li S, Ho CT, Chang YH, Tan KT, et al. (2016) Tangeretin derivative, 5-acetyloxy-40-tetramethoxyflavone induces G2/M arrest, apoptosis and autophagy in human non-small cell lung cancer cells in vitro and in vivo. Cancer Biol Ther 17: 48-64.

53. Hirano T, Abe K, Gotoh M, Oka K (1995) Citrus flavone tangeretin inhibits leukaemic HL-60 cell growth partially through induction of apoptosis with less cytotoxicity on normal lymphocytes. Br J Cancer 72: 1380-1388.

54. Morley KL, Ferguson PJ, Koropatnick J (2007) Tangeretin and nobiletin induce G1 cell cycle arrest but not apoptosis in human breast and colon cancer cells. Cancer Lett 251: 168-178.

55. Amin ARM, Karpowicz PA, Carey TE, Arbiser J, Nahta R, et al. (2017) Evasion of anti-growth signaling: A key step in tumorigenesis and potential target for treatment and prophylaxis by natural compounds. Semin Cancer Biol 35: S55-S77.

56. Tebou PL, Tamokou JD, Ngnokam D, Voutquenne-Nazabadioko L, Kuiate JR, et al. (2017) Flavonoids from Maytenus buchananii as potential cholera chemotherapeutic agents. S Afr J Bot 109: 58-65.

57. Oršolic N, Karac I, Sirovina D, Kukolj M, Kunštic M, et al. (2016) Chemotherapeutic potential of quercetin on human bladder cancer cells. J Environ Sci Health A, 51: 776-781.

58. Li Y, Meeran SM, Patel SN, Chen H, Hardy TM, et al. (2013) Epigenetic reactivation of estrogen receptor-a (ERa) by genistein enhances hormonal therapy sensitivity in ERa-negative breast cancer. Mol Cancer 12: 1.

59. Paterni I, Bertini S, Granchi C, Macchia M, Minutolo F (2013) Estrogen receptor ligands: A patent review update. Expert Opin Ther Pat 23: 1247-1271.

60. Crooks PA, Worthen DR, Ghosheh OA (2001) Use of the naturallyoccurring quinones thymoquinone and dithymoquinone as antineoplastic and cytotoxic agents. Pharmaceutical Sciences Faculty Patents 72.

61. Rahmani AH, Alzohairy MA, Khan MA, Aly SM (2014) Therapeutic implications of black seed and its constituent thymoquinone in the prevention of cancer through inactivation and activation of molecular pathways.

62. Chen SS, Michael A, Butler-Manuel S (2012) Advances in the treatment of ovarian cancer - a potential role of anti-inflammatory phytochemicals. Discovery Medicine 13: 7-17.

63. Majee SB, Khattry V, Agarwal V, Biswas GR (2016) Polyphenols derived from four indigenous Indian fruits for cancer chemoprevention and chemotherapy. J Med Plants Res 10: 838-847.

64. Panth N, Manandhar B, Paudel KR (2017) Anticancer Activity of Punica granatum (Pomegranate): A Review. Phytother Res 31: 568-578.

65. Luo M, Liu Q, He M, Yu Z, Pi Z, et al. (2017) Gartanin induces cell cycle arrest and autophagy and suppresses migration involving PI3K/Akt/ mTOR and MAPK signalling pathway in human glioma cells. J Cell Mol Med 21: 46-57.

66. Zhang C, Yu G, Shen Y (2017) The naturally occurring xanthone amangostin induces ROS-mediated cytotoxicity in non-small scale lung cancer cells. Saudi J Biol Sci [In press].

67. Bizzarri M, Dinicola S, Bevilacqua A, Cucina A (2016) Broad Spectrum Anticancer Activity of Myo-Inositol and Inositol Hexakisphosphate. Int J Endocrinol 2016: 5616807.

68. Grattan BJ Jr (2013) Plant sterols as anticancer nutrients: evidence for their role in breast cancer. Nutrients 5: 359-387.

69. Wu J, Ding Y, Chen CH, Zhou Z, Ding C, et al. (2016) A new oridonin analog suppresses triple-negative breast cancer cells and tumor growth via the induction of death receptor 5. Cancer Lett 380: 393-402. 
70. Chaudhary S, Chandrashekar KS, Pai KS, Setty MM, Devkar RA, et al. (2015) Evaluation of antioxidant and anticancer activity of extract and fractions of Nardostachys jatamansi DC in breast carcinoma. BMC Complement Altern Med 15: 50.

71. Wang P, Li Q, Li K, Zhang X, Han Z, et al. (2012) Betulinic acid exerts immunoregulation and anti-tumor effect on cervical carcinoma (U14) tumor-bearing mice. Pharmazie 67: 733-739.

72. Ahmad S, Sukari MA, Ismail N, Ismail IS, Abdul AB, et al. (2015) Phytochemicals from Mangifera pajang Kosterm and their biological activities. BMC Complement Altern Med 15: 83.

73. Munagala R, Kausar H, Munjal C, Gupta RC (2011) Withaferin A induces p53-dependent apoptosis by repression of HPV oncogenes and upregulation of tumor suppressor proteins in human cervical cancer cells. Carcinogenesis 32: 169-1705.

74. Valiahdi SM, Iranshahi M, Sahebkar A (2013) Cytotoxic activities of phytochemicals from Ferula species. Daru 21:39.

75. Bao R, Shu Y, Wu X, Weng H, Ding Q, et al. (2014) Oridonin induces apoptosis and cell cycle arrest of gallbladder cancer cells via the mitochondrial pathway. BMC Cancer 14: 217.

76. United States Department of Agriculture (n.d.) Agriculture research service. USDA food composition databases.

77. Jiang WG, Sanders AJ, Katoh M, Ungefroren H, Gieseler F, et al. (2015) Tissue invasion and metastasis: Molecular, biological and clinical perspectives. Semin Cancer Biol 35: S244-S275.

78. Jang E, Kim BJ, Lee KT, Inn KS, Lee JH (2015) A survey of therapeutic effects of Artemisia capillaris in liver diseases. Evid Based Complement Alternat Med.

79. Edwards V, Benkendorff K, Young F (2012) Marine compounds selectively induce apoptosis in female reproductive cancer cells but not in primary-derived human reproductive granulosa cells. Marine Drugs, 10: 64-83.

80. Zarogoulidis P, Tsakiridis K, Karapantzou C, Lampaki S, Kioumis I, et al. (2015) Use of proteins as biomarkers and their role in carcinogenesis. J Cancer 6: 9-18.

81. Standish LJ, Dowd F, Sweet E, Dale L, Weaver M, et al. (2016) Breast cancer integrative oncology care and its costs. Integr Cancer Ther AprilJune: 1-11.

82. Xie B, Nagalingam A, Kuppusamy P, Muniraj N, Langford P, et al. (2017) Benzyl Isothiocyanate potentiates p53 signaling and antitumor effects against breast cancer through activation of p53-LKB1 and p73-LKB1 axes. Sci Rep 7: 40070 .

83. Bai LY, Chiu CF (2016) A triterpenoid from wild bitter gourd inhibits breast cancer cells. Sci Rep 6: 22419.

84. Stojko RA, Dzik KA, Modzierz A, Kubina R, Wojtyczka RD, et al. (2015) Caffeic acid phenethyl ester and ethanol extract of propolis induce the complementary cytotoxic effect on triple-negative breast cancer cell lines. Molecules 20: 9242-9262.

85. Moirangthem DS, Laishram S, Borah JC, Kalita MC, Talukdar NC (2014) Cephalotaxus griffithii Hook f. needle extract induces cell cycle arrest, apoptosis and suppression of hTERT and hTR expression on human breast cancer cells. BMC Complement Altern Med 14: 305.
86. Lay MM, Karsani SA, Mohajer S, Malek SNA (2014) Phytochemical constituents, nutritional values, phenolics, flavonols, flavonoids, antioxidant and cytotoxicity studies on Phaleria macrocarpa (Scheff.) Boerl fruits. BMC Complement Altern Med 14: 152.

87. Abdullah AH, Mohammed AS, Abdullah R, Mirghani MES (2015) Oxidative stress-mediated apoptosis induced by ethanolic mango seed extract in cultured estrogen receptor positive breast cancer MCF-7 cells. Int J Mol Sci 16: 3528-3536.

88. Abdullah AH, Mohammed AS, Abdullah R, Mirghani MES, Al-Qubaisi M (2014) Cytotoxic effects of Mangifera indica L. kernel extract on human breast cancer (MCF-7 and MDA-MB-231 cell lines) and bioactive constituents in the crude extract. BMC Complement Altern Med 14: 199.

89. Arya RK, Singh A, Yadav NK, Cheruvu SH, Hossain Z, et al. (2015) Antibreast tumor activity of Eclipta extract in-vitro and in-vivo: Novel evidence of endoplasmic reticulum specific localization of Hsp60 during apoptosis. Sci Rep 5: 18457.

90. Taha H, Looi CY, Arya A, Wong AA, Wong WF, et al. (2015) Benzopyran derivatives from Pseuduvaria monticola induce mitochondrial-mediated apoptosis in human breast adenocarcinoma cells. PLoS ONE 10: e0126126.

91. Kakar SS, Ratajczak MZ, Powell KS, Moghadamfalahi M, Miller DM, et al. (2014) Withaferin A alone and in combination with cisplatin suppresses growth and metastasis of ovarian cancer by targeting putative cancer stem cells. PLoS ONE 9: e 107596.

92. Nagalingam A, Kuppusamy P, Singh SV, Sharma D, Saxena NK (2014) Mechanistic elucidation of the antitumor properties of withaferin a in breast cancer. Cancer Res 74: 2617-2629.

93. Mondal J, Panigrahi AK, Khuda-Bukhsh AR (2014) Anticancer potential of Conium maculatum extract against cancer cells in vitro: Drug-DNA interaction and its ability to induce apoptosis through ROS generation. Pharmacogn Mag 10: S524-S533.

94. Thacker PC, Karunagaran D (2015) Curcumin and emodin downregulate TGF- $\hat{I}^{2}$ signaling pathway in human cervical cancer cells. PLoS One 10: e0120045.

95. Rah B, Amin H, Yousuf K, Khan S, Jamwal G, et al. (2012) A novel MMP-2 inhibitor 3-azidowithaferin A (3-azidoWA) abrogates cancer cell invasion and angiogenesis by modulating extracellular Par-4. PlosONE 7: e44039.

96. Zhang X, Samadi AK, Roby KF, Timmermann B, Cohen MS (2012) Inhibition of cell growth and induction of apoptosis in ovarian carcinoma cell lines CaOV3 and SKOV3 by natural withanolide Withaferin A. Gynecol Oncol 124: 606-612.

97. Ting Y, Jiang Y, Ho CT, Huang Q (2014) Common delivery systems for enhancing in vivo bioavailability and biological efficacy of nutraceuticals. J Funct Foods 7: 112-128.

98. Henning SM (2012) Quercetin to enhance the bioavailability and activity of green tea polyphenols in vitro and in vivo. Food Funct 3: 635-642.

99. Wilson AJ, Saskowski J, Barham W, Khabele D, Yull F (2015) Microenvironmental effects limit efficacy of thymoquinone treatment in a mouse model of ovarian cancer. Mol Cancer 14: 192. 